\title{
The french approach to managing water resources in the mediterranean and the new European Water Framework Directive
}

\author{
Yves Henocque* and Bruno Andral
}

Institut Français de Recherche pour l'Exploitation de la MER (IFREMER), B.P. 330 83507, La Seyne sur Mer Cedex, France

*: Corresponding author : Tel.: +33-4-9430-4907; fax: +33-4-9406-5529

\begin{abstract}
:
The main content of the new European Water Framework Directive is presented. Within its river basin management approach, a special mention of coastal waters status is made. Among the issues at stake are the setting up of river basin management plans, including coastal waters, and water quality assessment system leading to an harmonized definition of quality objectives and their appropriate indicators. The Rhone-Mediterranean-Corsica Water Master Plan, launched in 1996, is considered to be well fitted to this river basin approach and the necessary tools which go with it. It shows up how a river quality assessment system (SEQ) can be adapted to the coastal waters and how it can progressively lead to an efficient set of publishable environmental and performance indicators. Since planning and implementation are devolved to the lowest appropriate level, a close look is then been given at how such a system can work at the local level through different selected case studies on the French Mediterranean coast. In conclusion, some guidelines are drawn up for future initiatives towards integrated coastal area and river basin management.
\end{abstract}

Keywords: Integrated management; River basin; Coastal zone; Quality assessment; Indicators 


\section{Introduction}

While the European Commission published in 2000 an in depth-report in which it outlined plans for an integrated coastal zone management (ICZM) strategy for the Union, the European Union adopted a directive on water quality called the Water Framework Directive which addresses the problems of coastal pollution by taking a common sense but innovative approach based on individual river basins as the starting point for protecting the inland and coastal waters. River basin management links up all the different national, regional and local stakeholders who have an impact on water supplies as they flow from mountain springs into lakes and rivers into the sea. As far as the coastal zones are concerned, the water framework directive will ensure that Member States take coherent steps to tackle all sources of pollution, whether from the land or the sea. The legislation gives governments a 15-year deadline for achieving good quality coastal waters through coherent water quality policies based on river basin management.

In France, the new Water Act (1992) lead to the institution of Water Management Master Plans for the six national hydrographic basins. The aim of these Master Plans is to define a balanced management of water resource and its drainage basin in order to satisfy or conciliate the different uses (agriculture, fisheries, aquaculture, industry, energy production, tourism, etc.) and their needs from the highlands down to the coast. As an example, the RhoneMediterranean-Corsica (RMC) Water Master Plan, issued in 1996, is based on :

- A comprehensive environmental assessment of the state of the drainage basin presented as a series of maps published as an atlas of the Rhone-Mediterranean-Corsica (RMC) drainage basin ;

- The consultations with the different Basin Committee geographic commissions (geographic and thematic) ;

- The sectoral consultations with the representatives of water distribution, leisure activities and fisheries, associations for nature protection, extraction activities, energy producers, industry and agriculture ;

- The consultations with concerned administrations and water technical committees ;

- The technical consultations carried out with local governments (Region, Department, Municipalities) ;

- The political consultations with local governments and national authorities (Interministerial Water Commission, National Water Committee).

In the following presentation, a parallel is drawn between the main features of the European Water Framework Directive and the orientations and current activities carried out in the frame of the RMC Water Management Master Plan.

\section{The European Water Framework Directive}

\section{Main features}

\section{Context}

About thirty different European directives or decisions have been made since 1975 for combatting water pollution following a double approach consisting in reducing hazardous substances runoffs into aquatic environments and defining quality standards for specific areas. Following the important directives on urban used waters and nitrates from agriculture activities (1991), Members States started to consider the real efficiency of their water policy and the necessary harmonization of the numerous directives. In 1995, the European Council 
and Parliament adopted conclusions requiring inter alia the drawing up of a framework Directive establishing the basic principles of sustainable water policy in the European Union and inviting the European Commission to come forward with a proposal. The final version was adopted in September 2000 after three years of discussion.

\section{Objectives}

Among the objectives of a sustainable water policy (water supply, environment protection and reduction of floods and droughts), priority is given to the environmental protection. Member States are required to develop operational programmes aiming at getting a good quality status of waters (surface waters, groundwaters, coastal waters) within the next 15 years. This objective is underpinned by a good ecological and chemical status of surface waters and a good quantitative and chemical status of groundwaters.

\section{Content}

In order to achieve these objectives, a framework for the protection of inland surface waters, transitional waters, coastal waters and groundwater has been established emphasizing that :

- Pollution prevention and control is based on a combined approach using control of pollution at source through the setting of emission limit values and of environmental quality standards ;

- Emission or loss of priority hazardous substances must cease or be phased out taking into account all significant sources and identifying the cost-effective and proportionate level and combination of controls.

Member States are asked to identify the individual river basins lying within their national territory and assign them to individual River Basin Districts. Small river basins may be combined with larger river basins or joined with neighbouring small basins to form a specific River Basin District. Groundwaters and coastal waters as well shall be identified and assigned to the nearest or most appropriate River Basin District or Districts. In each District, appropriate institutional arrangements, including the competent authority, must be put in place for the application of the rules of the Directive and the development of a detailed planning for management. Member States are thus required to make operational the programmes of measures specified in the River Basin Management Plan in order to achieve, in a period of 15 years, the overall objective of good quality status of the different water bodies, i.e. surface waters, groundwaters, and coastal waters.

\section{Planning measures}

Member States are asked to undertake in each River Basin District, an analysis of its characteristics, a review of the impact of human activity on the status of the different water bodies, and an economic analysis of water use. Programmes must include measures already set out in the different Directives (integrated pollution prevention and control, urban wastewater treatment, nitrates from agriculture, etc.) and additional measures like voluntary agreements or best environmental practices guidelines.

In each district, a register of protected areas must be established within the next 4 years following the publication of the Water Framework Directive. This includes all areas which have been designated under specific Community legislation for the protection of surface waters and groundwaters or for the conservation of aquatic habitats and species. These protected areas as well as the different water bodies must be monitored in order to get a comprehensive overview and follow-up of water status within each River Basin District.

Member States shall also ensure by 2010 that water pricing policies provide adequate incentives for users regarding the environmental objective of the Directive, and an adequate 
contribution of the different water uses (industry, households, agriculture...) to the recovery of water services costs taking account of the polluter pays principle.

\section{Implementation}

A River Basin Management Plan must be produced for each delimitated District. It may be supplemented by the production of more detailed programmes or plans for sub-basin, sector, issue, or water type, to deal with particular aspects of water management.

Active involvement of all interested parties and the public is encouraged by publishing the drafting of the plan and making it available for their comments, including :

- a timetable and work programme for the production of the plan with a statement of the consultation measures to be taken, at least 3 years before the beginning of the period to which the plan refers ;

- an interim overview of the significant water management issues identified in the river basin, at least 2 years before the beginning of the period to which the plan refers ;

- and draft copies of the River Basin Management Plan, at least 1 year before actual implementation.

In order to assist the Water Framework Directive implementation, the EU Member States and the European Commission have developed the Water Framework Directive "Common Implementation Strategy" which was agreed in May 2001 and which is built around four key activities: Sharing of information, Management of information and data, Development of guidance on technical issues, and Application, testing and validation of guidance. This initiative is seen by the different stakeholders as rather new and contrasting with the approach to implementation of other EU environmental protection legislation, where the focus has tended to be on disciplinary measures for failure to meet deadlines and objectives.

\section{Characterization and typology of surface waters}

Member States are asked to identify the location and boundaries of bodies of surface water carrying out their initial characterization as followed :

- the surface water bodies within the river basin district shall be identified as falling within either one of the following categories -rivers, lakes, transitional waters (estuary, delta, etc.) or coastal waters ;

- each category shall then be differentiated according to type. These types are those defined using two different systems (A and B) according to the choice made by the Member State ;

Systems A and B typology in the case of coastal waters :

System A :

Fixed typology :

Ecoregion

Type

\section{Descriptors}

Baltic sea

Barents sea

Norwegian sea

North sea

North Atlantic Ocean

Mediterranean sea

Based on mean annual salinity

$<0.5 \%$ Freshwater

0.5 to $5 \%$ Oligohaline

5 to $<18 \%$ Mesohaline 


\begin{tabular}{|c|c|}
\hline & $\begin{array}{l}18 \text { to }<30 \% \text { Polyhaline } \\
30 \text { to }<40 \% \text { Euhaline } \\
\text { Based on mean depth } \\
\text { Shallow waters }<30 \mathrm{~m} \\
\text { Intermediate }(30 \text { to } 200 \mathrm{~m} \text { ) } \\
\text { Deep }>200 \mathrm{~m}\end{array}$ \\
\hline \multicolumn{2}{|l|}{ System B } \\
\hline $\begin{array}{l}\text { Alternative } \\
\text { Characterization }\end{array}$ & $\begin{array}{l}\text { Physical and chemical factors that determine the } \\
\text { characteristics of the coastal water and hence the } \\
\text { Biological community structure and composition }\end{array}$ \\
\hline \multirow[t]{4}{*}{ Obligatory factors } & latitude \\
\hline & Longitude \\
\hline & Tidal range \\
\hline & Salinity \\
\hline \multirow[t]{8}{*}{ Optional factors } & Current velocity \\
\hline & Wave exposure \\
\hline & Mean water temperature \\
\hline & Mixing characteristics \\
\hline & Turbidity \\
\hline & Retention time (of enclosed bays) \\
\hline & Mean substratum composition \\
\hline & Water temperature range \\
\hline
\end{tabular}

Once such a classification of surface water bodies is made and thanks to appropriate monitoring programmes, Member States are asked to define the surface waters status (as well as groundwaters) following a list of criteria and parameters related to Biological characteristics, Hydromorphological elements supporting the biological characteristics (morphological conditions, tidal regime), Chemical and physico-chemical characteristics, and specific pollutants as defined by the Directive. An detailed example is given in Annex 1 for coastal waters.

\section{The French approach to managing water resources}

\section{Main features}

The French approach recognizes that water has no political or administrative boundaries. Management is thus organized on the basis of natural physiographic units river basins. It also cuts across sectoral considerations and involve stakeholders. Local communities, large regional developers, industrialists, farmers, water suppliers, fishermen, fish farmers, and conservation organisations act as partners with the government (Water Agencies) in setting policy that seeks to optimize benefits from the resources (taxes) while maintaining ecosystem integrity.

For that purpose, the new national legislation (Water Act, 1992) provides an institutional, regulatory, financial, and technical framework for multi-sectoral management at the scale of catchments. Master Plans (SDAGE) consistent with national legislation are formulated at the river basin level and implemented at the local level through local water management plans (SAGE). Thus, planning and implementation are devolved to the lowest appropriate level, where appropriation is possible. At all three levels (national, regional or river basin, local) there are institutional arrangements for stakeholders dialogue that involve representatives 
from other management levels (sectors, land-use management, etc), providing vertical integration between policies. All planning processes are supported by a reticulated (river basin level) national technical information system (RNDE) that provides for effective data access and exchange.

Long-term effectiveness of the management plans is secured through a system of taxes and therefore sustainable financing. As a matter of fact, Water Agencies are funded on the basis of the user-pays / polluter-pays principle and are financially autonomous from their own trust ministry, the Ministry of Spatial Planning and Environment.

\section{The Rhone-Mediterranean-Corsica basin example}

\section{Context}

The Rhone-Mediterranean-Corsica (RMC) basin area has a population of 13 million distributed in 8000 municipalities and fully or partly covering five different administrative regions: Corsica, Provence-Alpes-Cote d'Azue (PACA), Languedoc-Roussillon, RhoneAlpes, and Franche-Comté.

In the two Mediterranean regions, PACA and Languedoc-Roussillon, as a result of internal migrations, urbanisation has been continuously growing since 40 years, especially within their coastal zone. With a rather low industrialisation rate and employment decrease in agriculture, these regions are characterized by one of the highest unemployment rates in the country (13 to $14 \%)$. In this context, tourism industry is crucial for the regional economy owing to both domestic and international visiting tourists $(+75 \%$ of the total population during summer months). The energy production is concentrated along the Rhone river, leading by far to the largest intake of surface waters (71\% of the RMC basin total intake in relation to $7 \%$ for other industrial purposes) for thermal or nuclear plants cooling.

\section{Delimitation of boundaries}

The Water Master Plan (SDAGE) defines 29 sections based on structured territories. The coastal section includes the entire Mediterranean French coastal area between the Spanish and Italian borders, including the island of Corsica. The terrestrial delimitation of this coastal area corresponds with the boundaries of the closest watershed area, while the marine area estends towards the presumed area of influence of the discharged waters (the $100 \mathrm{~m}$ bathymetric line). Furthermore, the coastal strip has been divided in 50 zones with coherent management units. Each one of these units constitutes a homogeneous zone from the point of view of characteristics and management focus. A multi-criteria analysis was used for the identification of zones including four sets of information: physical, ecological, human uses and environmental problems, in this case focused on pollution. On this basis, a typology (10 different types) of the 50 zones has been elaborated.

\section{Monitoring the coastal waters}

The Mediterranean sea is the last media in which converge all the runoffs and inputs from the RMC drainage basin. It is considered as an integral part of the RMC hydrographic basin and as such must be managed in continuity with the policies applied to the inland waters.

The quality of coastal and marine waters is measured from 5 main monitoring networks :

- the Marine Bathing Water Monitoring Network operated by the Offices for Health and Social Affairs in each department (DDASS). Usually the sampling takes place from May to September and is focused mainly on microbiological parameters ;

- the National Marine Environment Monitoring Network (RNO) monitors levels of and trends in the main pollutants (heavy metals, organochlorine substances and PAHs) and general environment quality parameters (temperature, salinity, nutrients, chlorophyll); 
- the Microbiological Monitoring Network (REMI) monitors levels of and trends in faecal contamination by measuring faecal coliforms occurring in molluscs ;

- the Phytoplancton Monitoring Network (REPHY) monitors phytoplancton populations and particularly species that are toxic for humans or marine organisms ;

- the Posidonia Monitoring Network is a regional one, currently limited to the PACA region. It monitors the extension or regression of seagrass beds from the nearshore to their lower limit of development (40 meters).

In spite of these monitoring networks, it is still difficult to get a clear picture of the quality of the coastal waters and to relate precisely the contamination observed with the different inputs coming from inland waters. Within the SDAGE framework, it has therefore been decided to define a new global monitoring network, the Coastal Mediterranean Network (RLM: Reseau Littoral Mediterraneen) in order to coordinate and complete the already existing networks. This network will be crucial in feeding the coastal Quality Assessment System (SEQ) under development.

\section{Surface waters quality status}

Since 1992, a new system for assessing the river waters quality has been put in place at the national level. It has the following characteristics: applicable to all types of river systems in order to allow diagnostic comparison, adaptive by integrating new knowledge, and polyvalent for different uses and types of product (definition of actions, public information, decisionmaking). The system is made of three components : water physicochemistry , physical charracteristics (hydromorphology and hydrology), and biological communities. For each of these three components, there is a double assessment defining the quality as an alteration, a criteria or an indicator, and the effects of the quality state on the ecosystem functions and human uses. For example, in the case of water, biological potentialities and uses such as drinking water production, agriculture, leasures and aquatic sports, etc., are taken into account. This tool (water quality status assessment) is part of the planning strategy allowing the setting up of precise objectives and their implementation monitoring.

In the case of coastal waters, there is no overall quality assessment system till today although a large survey has recently showed up that stakeholders and decision-makers are asking for such a tool. Therefore, in the frame of the SDAGE, an important work is currently carried out on the definition of a system similar to the river waters one. Its main functions would be :

- To assess coastal ecosystems quality through the measurement of their ecological status and the corresponding human uses potentialities;

- To carry out environmental diagnostic identifying the main factors of ecosystems potentialities and uses;

- To contribute to the planning of actions for preservation / restoration of ecosystems and their use, through the different phases of definition, implementation and evaluation (in reference to the objectives).

\section{Implementation and follow-up}

The RMC Water Master Plan (SDAGE-RMC) has been adopted in December 1996. It is based on ten major orientations as followed :

1. Keep on combatting any kind of pollution ;

2. Guarantee water quality required by the different uses ;

3. Underline the strategic status and vulnerability of groundwaters ;

4. $\quad$ Better management before investing ;

5. $\quad$ Respect the milieux natural functioning ;

6. Restore or Preserve the outstanding aquatic systems ; 
7. Restore urgently the most degraded milieux ;

8. $\quad$ Promote a more efficient risks management ;

9. Think water management in terms of land-use development ;

10. Enhance local and participative management.

These orientations have been developed in detail in the Master Plan (operational measures, management guidelines in regard of the existing legislation, specific objectives in relation with the different territories, SAGE guidelines for local management) for the different type of aquatic systems as described above and for each of the 29 territories composing the RMC watershed, the 29th being the coastal area itself as defined earlier.

After three years of implementation (1997-1999), and in order to get an overview of what has been achieved, the best way is to look at the first set of indicators which have been set up under the coordination of the SDAGE technical secretariat, with the help of the Planning Commission and the SDAGE thematic groups. These indicators are of three types, describing the State of natural aquatic systems, the Pressure they support from human activities, and the Response given through actions corresponding to the SDAGE objectives. This latter type is also considered as the RMC-SDAGE Performance indicators. For each of the following themes, there can be one, two or three of the different types of indicators as mentioned before :

1. Quality of rivers and channels : if the situation has been significantly improved for the biggest rivers, many secondary rivers are still in a preoccupying state.

2. Combatting pollution : on a total treatment capacity of 35 Million/Equivalent/Inhabitant (MEH), 15 concerned urban pollution (efficiency rate: 68\%) and 20, industrial pollution treatment (efficiency rate: $80 \%$ ). This capacity has been increased in a range of 15\% between 1992 and 1997, but still an estimated $11 \mathrm{MEH}$ are directly discharged in rivers without any treatment.

3. Eutrophication : it is still an important issue for a large part of the RMC watershed, in spite of some improvements regarding the phosphorus concentration levels.

4. Toxic pollutions : since the water quality global assessment carried out in the frame of the SDAGE elaboration phase, knowledge of the contaminants and areas concerned has drastically improved, but there is still a need to better identify the pollution sources and relate them with the contaminants concentrations observed in the different aquatic systems.

5. Accidental pollution : indicators under development.

6. Physical state of rivers : generally speaking, restoration activities are very little. Lacking a physical Quality Assessment System (SEQ), the proposed indicators remain essentially qualitative and thus rather subjective.

7. Quantitative management of rivers : related to the rivers hydrology. In spite of abundant water resources coming from the mountain areas, there is sometimes an unequal distribution which can leads to a lack of water. Many hydroelectrical infrastructures, dams or artificial channels have still to be optimised in their management.

8. Flooding risks : generally speaking, the RMC basin is subject to climatic conditions (heavy rain-showers) which lead to more or less sudden flooding. Numerous studies at the scale of the great rivers axis have been carried out or are under completion for specific management plans.

9. Groundwaters : groundwaters feed about 2 billion m3/year or $75 \%$ of the current needs in drinkable water. Efforts are focused on the pollution abatement concerning nitrates (in more than 1000 municipalities) and pesticides.

10. Drinkable water avilability : is much depending on groundwaters quality with a lack of security in municipalities of less than 100,000 inhabitants. 
11. Wetlands : this theme is transversal to water resources management and natural systems conservation. It is considered as a highly prioritary objective for the entire watershed. One of the main actions concerns the carrying out of local inventories (scale: departement) in order to settle specific actions plans in concertation with stakeholders. Still, knowledge of these very specific areas is low and hardly allows a good quantification of indicators.

12. Species protection : the proposed indicators concern state indicators aiming at the knowledge of aquatic natural heritage and monitoring of aquatic species, and response indicators for assessment of protection measures and management of exploited species.

13. Coastal area : under the SDAGE objectives and guidelines, a number of local initiatives are currently under development. They are usually carried out by intermunicipalities structures and lead to actions plans devoted to environmental assessments, observatories and/or restoration of natural sites. In the latter case, one of the major institutional structure is represented by the National Coast and Lakeshore Conservation Agency (CELRL), a public body established in 1975 to conduct a land acquisition policy aimed at protecting the coast and natural sites, and maintaining ecological diversity. In 1998, the Agency had acquired a total of 30,436 ha (291 km of coastline) on the French Mediterranean coast, divided in 148 sites. In general, the sites owned by the Agency are managed by local authorities through contracted agreements.

\section{Lessons learned and recommendations}

Looking at the respective legislative frameworks for the coastal area and the river basin management, it is to be noticed that the most integrative tool between both is the Water Development and Management Master Plan (SDAGE) from the Water Act. In the case of France and more especially of the RMC river basin, one of the major reasons stems from the existence of a powerful (institutionally and financially) RMC Water Agency dealing with the entire French Mediterranean watershed.

If the initial aim of Water Agencies, established under the 1964 Water Act, was the restoration of the quality of freshwater and coastal waters, they actually focused until the early 1980s on controlling industrial and urban pollution thanks to their system of water charges (domestic and industrial). With their huge financial means (the rate of the water taxes were substantially increased under the Water Agencies 6th Action Programmes, 1992-1996), and the revised 1992 Water Act, they have been more and more taking into account sources of pollution hitherto ignored or inadequately dealt with like pollution of the natural environment by run-off rainwater, pollution from diffuse agricultural sources (nitrates, pesticides) and management of sewage sludge from waste water treatment plants.

In this context, and in the frame of the SDAGE preparation phase, the RMC Water Agency has been particularly active in promoting a whole basin approach through systematic spatialisation of territories including the coastal area. Regarding this latter, in tight collaboration with specialised agencies like Ifremer (French Research Institute for the Exploitation of the Sea), systematic spatial analysis integrating the information on the state (geomorphology, ecology) and pressure (human activities, inputs fluxes) specific to each geographic unit, allowed a comprehensive review of what was known about coastal areas contamination. The diagnostic lead to the conclusion that, in spite of the existing monitoring networks, a lot of informations were lacking about the precise state of pollution, its dynamic and its relation with the land-based sources of contamination. It was thus decided to increase the information exchange and coordination across the different agencies monitoring programmes (RLM: Mediterranean Coastal Network), as well as the use of more complex water quality modeling, data interpretation, and database management allowing a better 
dissemination towards decision makers and the public. Furthermore, it was decided to progressively pool the coastal area data with the inland waters one, within the regional component of the National Water Data Network (RNDE), a network of partners established in 1992 in order to optimise the description, production, collection, management, use and dissemination of data on water.

From the previous presentation, some general and useful recommendations may be drawn out for application to other areas in Europe or elsewhere :

- a strong watershed framework, from the headwaters to the receiving waters, is necessary. It can be done through a comprehensive watershed master plan on a large scale (RMC case: $130,000 \mathrm{~km}^{2}$ ) which specific provisions for smaller scale watersheds which are included ;

- watershed master plans are to characterize waters and land uses of the watershed concerned, identify water quality problems and goals for watershed management, allocate needed load reductions among point and nonpoint sources, and identify financial resources and institutional arrangements necessary for implementation ;

- the different involved administrations have to endorse the concept of cross-agency and inter-agencies ecosystem management initiatives, and support an ecosystem-based territories framework through which State, regional, local governments, the public, and Parliament (Congress) can work together to develop specific strategies, refocus current programmes and resources, and identify cost-effective investments for the economic and ecological health of a region ;

- in a way adapted to each national and regional contexts, a collaborative partnership has to be promoted in order to include the full spectrum of infrastructure agencies, resource management agencies, environmental protection agencies (both national and local), local, private, and citizen interests, towards the protection and restoration of inland and coastal ecosystems.

The EU Water Framework Directive (WFD), which must be transposed into national law by the end of 2003 at the latest, requires active management measures to deliver clear environmental objectives. Although establishing effective measures necessitates a degree of administration and planning, priority must be given to implementing action on the ground at river basin or sub-basin level. Thus, while meeting the WFD's process obligations is important, the overriding obligation is to achieve results. Over time, this distinction should be reviewed regularly by Member States, River Basin District (RBD) authorities and stakeholders, to ensure that WFD implementation remains results-focused and does not stagnate due to over-emphasis on administrative processes. The final deadlines for transposition into national law and achievement of "good status" mean that the timetable is tight and the need for action is urgent (WWF, 2001).

\section{References}

- WWF (2001). Elements of good practice in integrated river basin management. A practical resource for implementing the EU framework directive. World Wide Fund for Nature report.

- UNEP/MAP/PAP (1999). Conceptual framework and planning guidelines for integrated coastal area and river basin management. Split, Priority Actions Programme. 
- European Union (2000). Directive of the European Parliament and of the Council 2000/60/EC establishing a framework for community action in the field of water policy. PE-CONS 3639/1/00 Rev 1.

- UNEP/MAP/PAP (2001). Good practices guidelines for integrated coastal area management in the Mediterranean. Split, Priority Actions Programme, 2001.

- Henocque Y., Denis J. (2001). A methodological guide: steps and tools towards integrated coastal area management. IOC Manuals and Guides No 42, UNESCO. 